\title{
IDENTIFICATION OF MAPPING MODELS OF PLAYERS COOPERATION IN CREATING POINT SITUATIONS IN VOLLEYBALL DEPENDING ON SETTER POSITION
}

\author{
LESZEK MAZUR1, EDWARD SUPERLAK² \\ IDoctoral Studies, University School of Physical Education in Wroclaw, Faculty of Physical Education, \\ Wrocław, Poland \\ 2University School of Physical Education in Wroclaw, Faculty of Sport Science, \\ Department of Biological and Motor Bases of Sports, Wroctaw, Poland
}

Mailing address: Leszek Mazur, University School of Physical Education in Wroclaw, Faculty of Physical Education, 35 Paderewskiego Ave., 51-612 Wrocław, tel.: +48 71 3473485, fax: +48 71 3473433, e-mail: leszek.mazur@hotmail.com

\begin{abstract}
Introduction. Team games, which have been studied by researchers for several years, include both individual and cooperative actions. Although cooperation is the essence of team sports, there is still a dearth of research that has thoroughly explored the process of player cooperation. The aims of the current study are to identify the models of player cooperation in creating point situations depending on the position of the setter and evaluate the efficiency of this cooperation. The process of cooperation was analysed by means of praxeological models reproducing the game, considering the efficiency of the attack and the surprise effect on the opponent's block. Material and methods. A novel research method was used in this study, which is the qualitative study of unique cases. The material analysed was the observation sheets from matches played by the four best teams of the top Polish volleyball league in the 2013/14 season. Results. The observations yielded a large amount of data, which enabled us to identify models of cooperation in creating point situations depending on the position of the setter during the game. We also evaluated the reliability of the attack and the effectiveness of surprising the opponent's block. Conclusions. Each of the teams had a specific model mapping cooperation in creating point situations depending on the position of the setter on the court. Teams achieve different levels of attack reliability as well as of the surprise effect on the opponent's block in these interactions.
\end{abstract}

Key words: volleyball, cooperation, mapping models, creating point situations, reliability, attack

\section{Introduction}

Team games have been some of the most popular sports in the world for many years. The variability of actions, surprising developments, and unique solutions to the situations during matches contribute to the fact that team games are eagerly watched and practised by many people in the world. Contemporary team games are characterised by dynamic actions taken by the players on the court in relation to the current situation [1]. Team sports games can be regarded as regulators of the interests of the players, who, using the co-conscious and co-intuitive abilities of acting and interacting in the offence as well as counteracting in the defence, compete according to the rules in order to achieve uncertain individual, common, and opposing goals [2]. The essence of team games is cooperation. The players' individual activities are limited in favour of cooperative ones, which are completely dependent on the partners. Volleyball is the only game where activities which are relatively dependent on partners - that is those where the presence of partners is not necessary to perform a given action - are practically non-existent (the only such action is the serve). For this reason, the successful implementation of the cooperation process determines the level of effectiveness in this sport discipline. Cooperative teams can achieve goals that individual players would not be able to accomplish. There are few studies that have attempted to look at team games in a holistic way, in the context of cooperation. The contemporary literature presents many issues regarding the effectiveness of actions in the game [3, 4, 5, 6]; however, these papers focus on individual activities, not taking into account the context of interaction between players.

Volleyball is a discipline in which cooperation plays the most important role. Each action performed in the game is related to the previous one, which is why discipline experts often consider volleyball the most collaborative among all team games. Team sports have different game phases. Panfil [2] has distinguished three phases of the game in the offence, that is game positioning, creating point situations, and point scoring, and three phases in the defence, namely counteracting game positioning, counteracting creating point situations, and preventing scoring. The phase of creating point situations in the offence includes all actions relatively and absolutely dependent on the partners which make it possible to potentially score points. During point situations, the setter plays a very important role. Afonso et al. [7] considered this player to be the leader of the attack phase; after analysing the situation on the court, the setter makes correct decisions so as to surprise the opponent and enable the team to get a point. The scoring phase is related to the indicator of attack reliability. High attack reliability - understood as the quotient of all effective actions and the sum of all actions taken by the players - depends on the way the ball is set as well as on the surprise effect on the opponent. The place where the ball is set by the setter determines the level of the effectiveness of the team's various ways of interacting. Therefore, an attempt was made in the current study to identify 
the cooperation of players with regard to the position, that is the location on the court, of the player acting as the setter. The actions of the setter, who is the most important player in the phase of creating point situations, are heavily dependent on the effectiveness of accepting the serve, including on the parabola of the set ball, its direction, the speed of its flight, and the place where it was received. The setter's position is therefore very important in the context of identifying models of player cooperation in creating point situations, and it also determines the level of the reliability of selected ways of cooperation.

The cooperation of the players in creating point situations, taking into account the setter's position on the court, has been presented in the form of praxeological models mapping team play. Praxeological models are defined as complex objects reflecting complex existing fragments of reality [8]. The cooperation of players in the game is a difficult process to identify because of its uniqueness and complexity, which is why presenting it in the form of mapping models seems to be reasonable. Praxeological models of the game are based on objectified and reliable observation of the game. The analysis of the current research results has made it possible to present the collected data in the form of selected cognitive models. Praxeological game models have already been used in the works of other authors [i.a., 9, 10, 11, 12]. The analysis of mapping models allows one to draw appropriate conclusions for sport practice. The models provide a certain scheme and can determine the direction of actions taken in creating design models, which can be used in the games of other sports teams.

The aims of the study were to identify and compare models mapping the cooperation of players in the phase of creating point situations in volleyball, taking into account the position (that is the location on the court) of the player acting as the setter, along with the evaluation of the efficiency of this cooperation. The efficiency of cooperation was evaluated using the criterion of the reliability of the combinations made in the attack.

In order to be able to accomplish the main aims of the research, we formulated the following research questions:

1. Which models of player cooperation were applied in creating the point situations and how did the models differ depending on the position of the setter on the court?

2. What was the reliability of the attack achieved by the teams in the cooperation models implemented depending on the position of the setter on the court?

3. What was the effectiveness of surprising the opponent's block depending on the position of the setter on the court?

\section{Material and methods}

The research material consisted of the observations of matches of the following four top-class men's teams in Poland: PGE Skra Bełchatów, Asseco Resovia Rzeszów, Jastrzębski Węgiel, and ZAKSA Kędzierzyn-Koźle. The study focused on players playing the role of the setter, expanding on the research of Mazur and Superlak [13], who analysed the actions of the setter from PGE Skra Bełchatów, N.U., by examining three more players, that is F.D. (Assecor Resovia Rzeszów), P.Z. (ZAKSA Kędzierzyn-Koźle), and M.M. (Jastrzębski Węgiel). The research included matches played between these teams in the main season of the top volleyball league in Poland in 2013/2014. These teams took the four top places in the competition. In total, 51 sets were analysed, in which 1,529 actions were observed.

We used the research method developed by Panfil and Superlak [14], that is a qualitative study of unique cases. The method is applicable in analysing complex, unique, and special entities, and in this case, these are teams (practising volleyball) having the highest levels of sport performance.

The research procedure included observing the matches along with recording particular actions of the players [13]. For this purpose, the court was divided into zones in which players' activities were identified (Fig. 1).

\begin{tabular}{|c|c|c|c|}
\hline POSITION 4 & POSITION 3 & POSITION 0 & POSITION 2 \\
\hline POSITION 4' & POSITION 3' & POSITION 0' & POSITION 2' \\
\hline POSITION 5 & POSITION 6 & & POSITION 1 \\
& & & \\
\hline
\end{tabular}

Figure 1. Division of the court into positions for observation of the setter's actions [13]

In order to record the data, including those concerning the identification of the players' actions in offensive situations, we used Panfil and Superlak's observation sheets [14] modified by Mazur and Superlak [13]. The sheet comprises quantitative criteria, including the number of combinations in the attack (described in the two works of Panfil and Superlak $[14,15])$, and qualitative criteria, as it contains an assessment of the degree of cooperation efficiency (effective, ineffective, or counter-effective) (see Tab. 1).

Table 1. Observation sheet for recording data regarding cooperation in the attack [13]

\begin{tabular}{|c|c|c|c|c|c|}
\hline \multirow{3}{*}{$\begin{array}{c}\text { Names } \\
\text { of combinations }\end{array}$} & \multicolumn{4}{|c|}{ Effectiveness of player cooperation } & $\begin{array}{l}\text { Block } \\
\text { surprise }\end{array}$ \\
\hline & \multicolumn{4}{|c|}{ Number of actions } & \multirow[b]{2}{*}{$\begin{array}{l}\text { Number } \\
\text { of actions }\end{array}$} \\
\hline & $\begin{array}{c}\text { All } \\
\text { actions }\end{array}$ & $\begin{array}{l}\text { Effective } \\
\text { actions }\end{array}$ & $\begin{array}{c}\text { Ineffective } \\
\text { actions }\end{array}$ & $\begin{array}{l}\text { Counter- } \\
\text { effective } \\
\text { actions }\end{array}$ & \\
\hline \multicolumn{6}{|l|}{ 1st tempo attack } \\
\hline \multicolumn{6}{|l|}{ Zone 4 attack } \\
\hline \multicolumn{6}{|l|}{ Zone 2 attack } \\
\hline \multicolumn{6}{|l|}{ Zone 1 attack } \\
\hline \multicolumn{6}{|l|}{ Pipe } \\
\hline $\begin{array}{c}\text { Attack after high bal } \\
\text { pass }\end{array}$ & & & & & \\
\hline
\end{tabular}

Selection and description of criteria and indicators for cooperation evaluation

The criterion for evaluating the efficiency of cooperation, understood in accordance with Panfil [16] as a collection of all the positive qualities of this cooperation, was its effectiveness. Therefore, the assessment of the efficiency of cooperation was made as follows: 
- effective - action ending with attacking and scoring a point;

- ineffective - action where the game continued, and the attack was defended;

- counter-effective - action ending with an incorrect attack and giving the opponent a point [13].

Two indicators of the efficiency of players' actions are used in this paper:

1) the attack reliability index (ARI) calculated using the following formula [17]:

ARI $=\frac{\sum \text { effective actions }}{\sum_{\text {all actions }}}$;

2) the block surprise index (BSI) calculated as follows [18]:

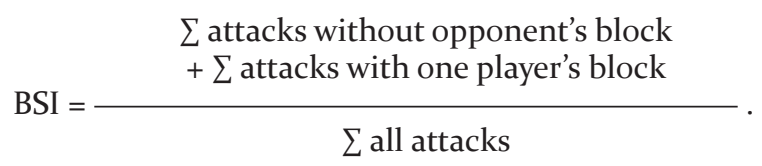

In addition, basic statistical values, that is averages and percentages, were computed.

\section{Results}

The observations of the matches made it possible to record the following number of actions for the selected setters: M.M. (Jastrzębski Węgiel) - 470, P.Z. (ZAKSA Kędzierzyn-Koźle) 452, F.D. (Asseco Resovia Rzeszów) - 390, and N.U. (PGE Skra Bełchatów) - 439. When making a quantitative evaluation of the actions of these players, we used an indicator in the form of the quotient of the total number of actions in individual positions of all the players and the sum of all actions taken by them, expressed as a percentage (see Fig. 2). Such a way of presenting the data made it possible to determine the positions in which the setters usually acted. Confirming the results of Mazur and Superlak's research [13], the players took the largest number of actions in positions 0,0 , and 3, which is why these three items were taken into account in the further analysis of the research results.

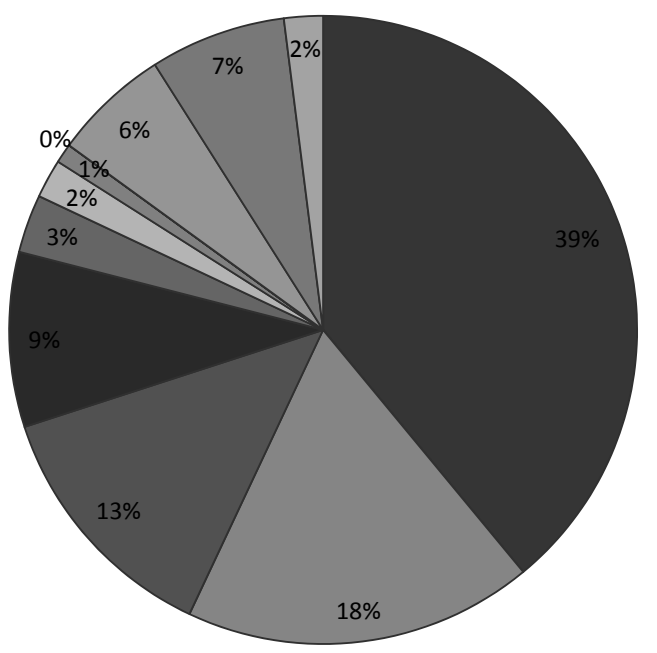

$\square$ Postion 0
$\square$ Postion 0'
$\square$ Postion 3
$\square$ Postion 3'
$\square$ Postion 2
$\square$ Postion 2'
$\square$ Postion 4
$\square$ Postion 4'
$\square$ Postion 1
$\square$ Postion 6
$\square$ Postion 5

Figure 2. Distribution of the percentages of actions (\%) for particular setter positions
Mapping models of player cooperation in the attack

After observing the players' actions and recording them on the observation sheets (see Tab. 1), we summed up the results and expressed them as percentages. Position 0 on the court, which is often called "the zone of the perfect receive" by experts in the discipline, is where the ball is most often passed after receiving the serve. This was also found to be the case in our research, since it is in the 0 position that the highest number of actions performed by the setters was recorded. During the analysis of the strategy of cooperation in this position, differences between selected teams were noticed. The most common way of cooperating in the attack of the teams of P.Z, M.M., and N.U. were "lst tempo attack" combinations (quick attacks played by predominantly middle blockers). In M.M.'s team, the proportion of these combinations, as compared to all other combinations played in this position, amounted to as much as $36 \%$. The percentage of this kind of cooperation in other teams in relation to the other combinations played was approximately $31 \%$. Significant differences were also noticeable in the use of "zone l attack" combinations, as the team of setter M.M. chose this type of cooperation definitely more often compared to the other teams under study ( $20 \%$ of all combinations in the attack) (see Fig. 3).

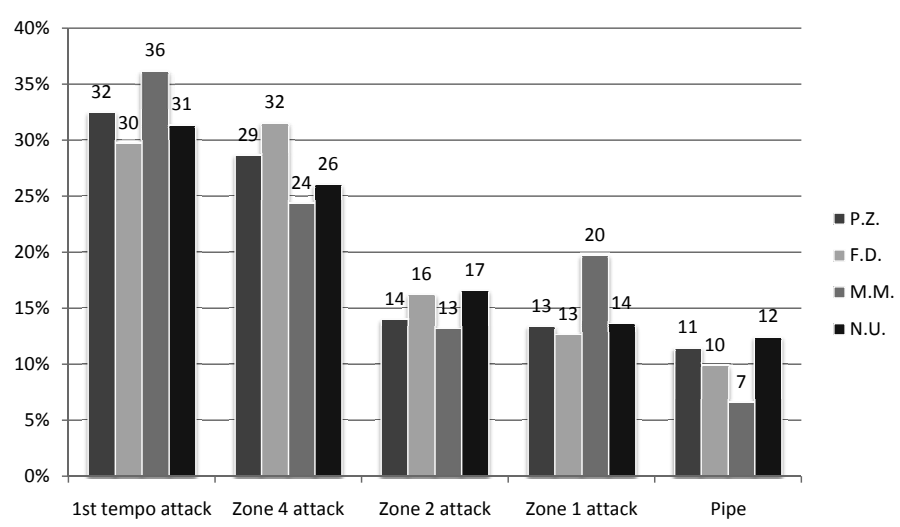

Figure 3. Percentage (\%) of combinations played in attack with setter in position 0

In position 3, even larger differences in the creation of point situations by the teams evaluated were observed. The most similar results were obtained in "pipe" combinations, their percentage being 9\% in all teams. An interesting fact is also the very heavy use of "lst tempo attack" combinations by the team of N.U. ( $46 \%$ of all combinations in the attack) and the frequent use of "zone l attack" combinations by M.M.'s team (see Fig. 4).

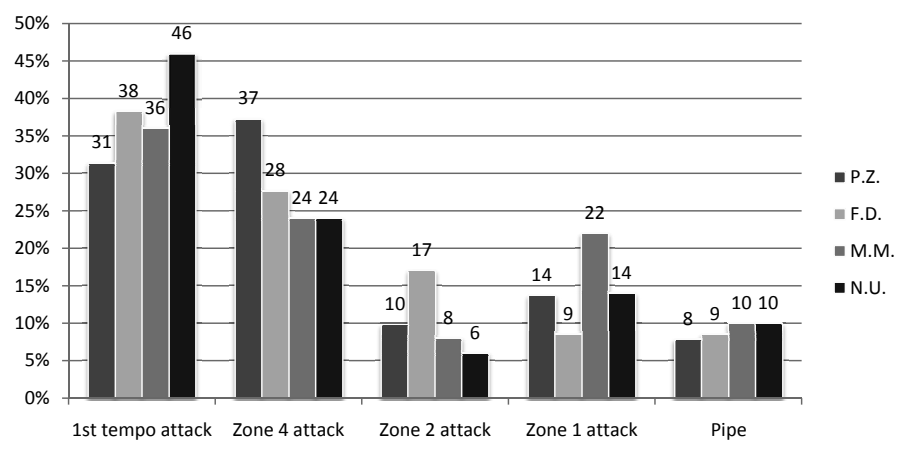

Figure 4. Percentage (\%) of combinations played in attack with setter in position 3 
Position 0' is a place on the court where the distance to the net is at least $1.5 \mathrm{~m}$ (see Fig. 1). When analysing the results of the research, we observed significant differences in the types of interaction chosen by each setter after the ball was played from this position. An interesting fact is the significant number of "lst tempo attack" combinations chosen by player M.M. (as many as $44 \%$ of all cooperation methods) as well as the small number of "zone 2 attack" combinations performed by the team of N.U. It is visible that the teams of F.D. and N.U. most often chose combinations where the so-called left wing (zone 4) was used (see Fig. 5).

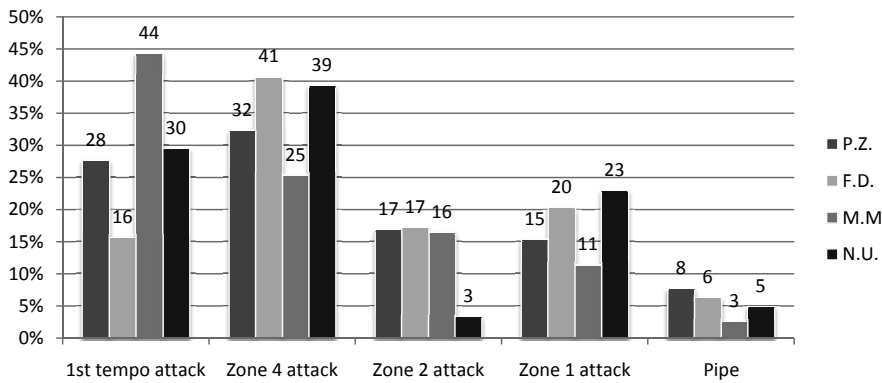

Figure 5. Percentage (\%) of combinations played in attack with setter in position 0 '

Models that reproduce player cooperation in creating point situations allow for identifying the differences and similarities in various ways of cooperating after the reception of the serve. The results obtained from the observations were summed up and expressed as percentages. The average percentage distribution of cooperation in the attack was also determined, and it was possible to compare it with the percentage distribution of this cooperation carried out by the teams observed. The results presented in the radar charts best show the differences between the teams and make it possible to identify significant differences in the phase of creating point situations.

The only team that significantly distinguished itself in creating point situations from position 0 was the team of M.M. Referring to the average distribution of the attack, this team decided to use "lst tempo attack" and "zone l attack" combinations more often and used "pipe" combinations least often. The cooperation of the other teams in the attack was similar and close to the average. More frequent combinations of "zone 4 attack" by F.D.'s team compared to other teams were observed (see Fig. 6).

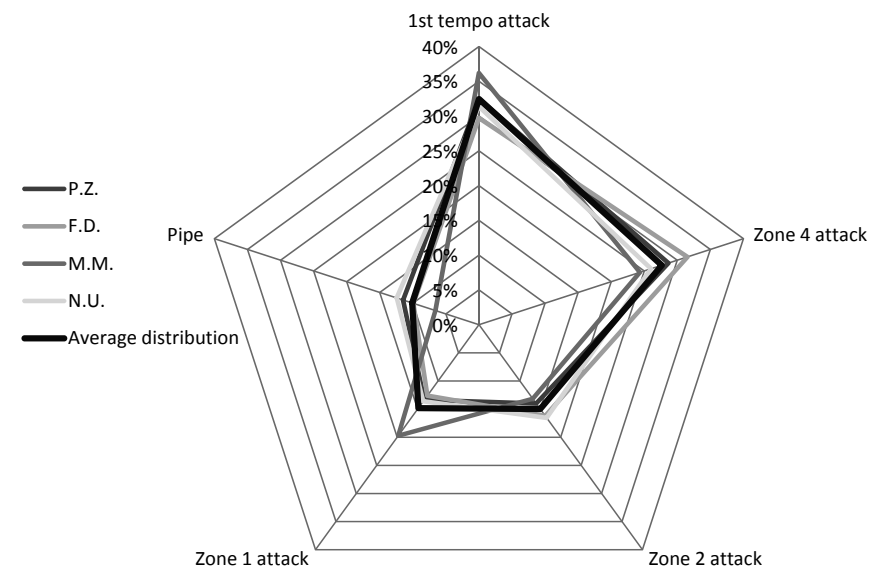

Figure 6. Percentage distribution (\%) of combinations played in attack with setter in position 0 (with average distribution)
Analysing the results of the research including the actions of the setters in position 3, we found large differences in the creation of point situations. Interestingly, each of the teams used one of the combinations much more frequently in relation to the average, and in each of the teams, this was a different way of cooperation. The greatest similarity among the teams was noted for "pipe" combinations. In addition, each team had a different model of cooperation in the attack with the setter in this position (see Fig. 7).

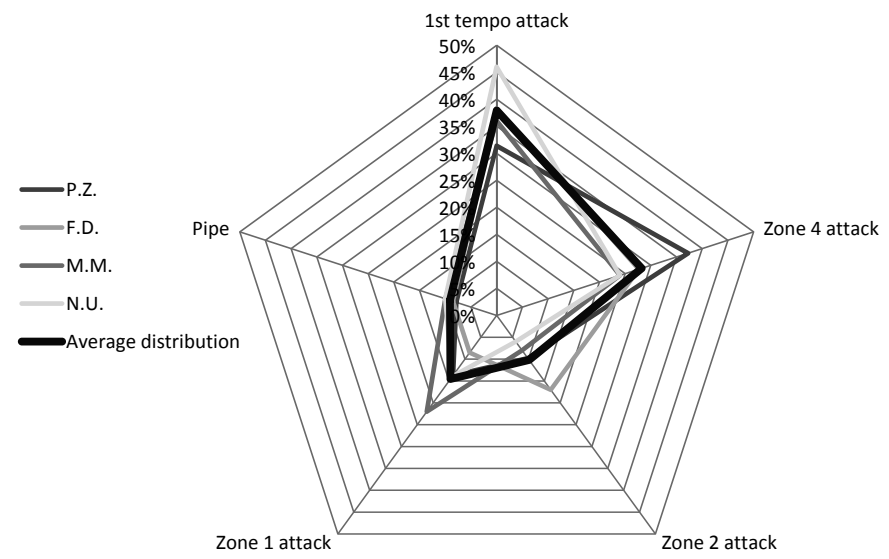

Figure 7. Percentage distribution (\%) of combinations played in attack with setter in position 3 (with average distribution)

In position 0', the number of "lst tempo attack" combinations in M.M.'s team was observed to be above the average value. There was also a small number of combinations of "zone 2 attack" in N.U.'s team and very large variation in the combinations of "zone 4 attack" in all teams (between 25\% and 41\%) (see Fig. 8).

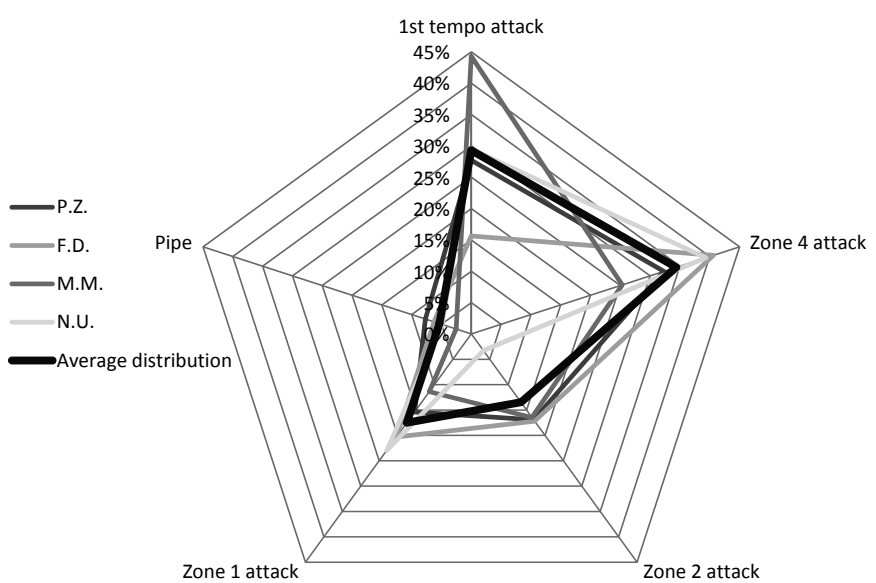

Figure 8. Percentage distribution (\%) of combinations played in attack with setter in position 0' (with average distribution)

\section{Reliability of cooperation in attack depending on set- ter position}

The attack reliability index (ARI) used in the current study was the quotient of the number of actions and the sum of all actions taken by the players expressed as a percentage. In the 0 position, attention should be paid to the high ARI in the "zone 
2 attack" and "zone 1 attack" combinations obtained by P.Z.'s team, amounting to $73 \%$ and $81 \%$, respectively. It is worth noting that the high value of the ARI index was obtained in "lst tempo attack" combinations by M.M's team, bearing in mind that it was the most commonly used combination in this position by this team. The lowest attack reliability index, apart from being obtained by the team of setter F.D., was achieved by the teams in "zone 4 attack" combinations (see Fig. 9).

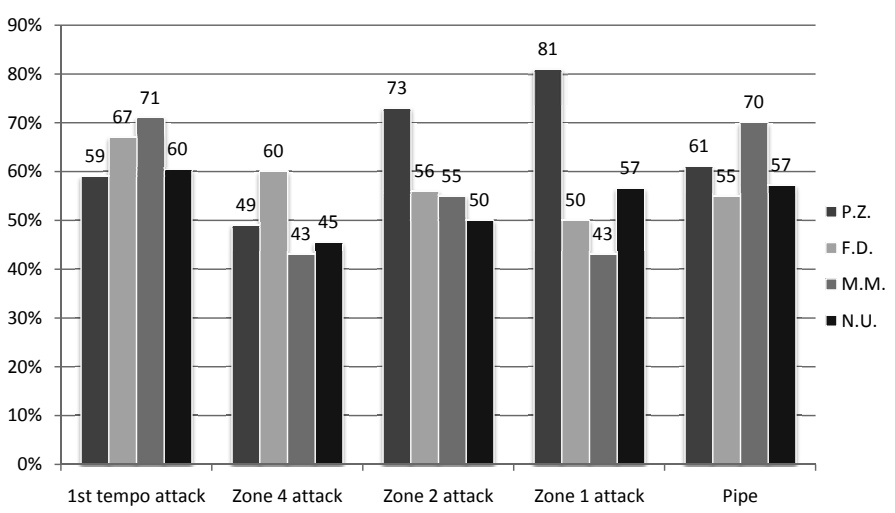

Figure 9. Cooperation reliability in particular combinations in attack (ARI) with setter in position 0

It is interesting to note the $100 \%$ reliability in the "zone 2 attack" combinations by the team of N.U. after they played from position 3, as well as high values of the ARI in the "pipe" combinations of all teams from this position. We also observed low reliability of the attack in "lst tempo attack" combinations obtained by the team of N.U. in comparison to other teams, as well as a low ARI in combinations of "zone 2 attack" of the teams of players F.D. and P.Z., in contrast to the teams of N.U. and M.M. (see Fig. 10).

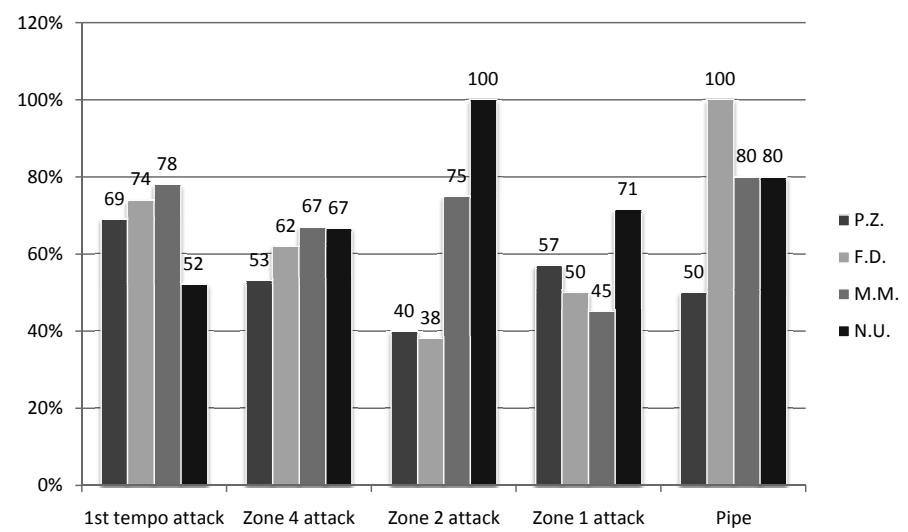

Figure 10. Cooperation reliability in particular combinations in attack (ARI) with setter in position 3

High attack reliability in all combinations was achieved by the team of setter P.Z. after playing in the 0' position. On the other hand, M.M.'s team achieved a low ARI value in "lst tempo attack" combinations, despite the fact that it was the most common way of cooperating in this team's attack. Nevertheless, this team achieved high values of attack reliability in combinations with the use of the wings and zone 1 (see Fig. 11).

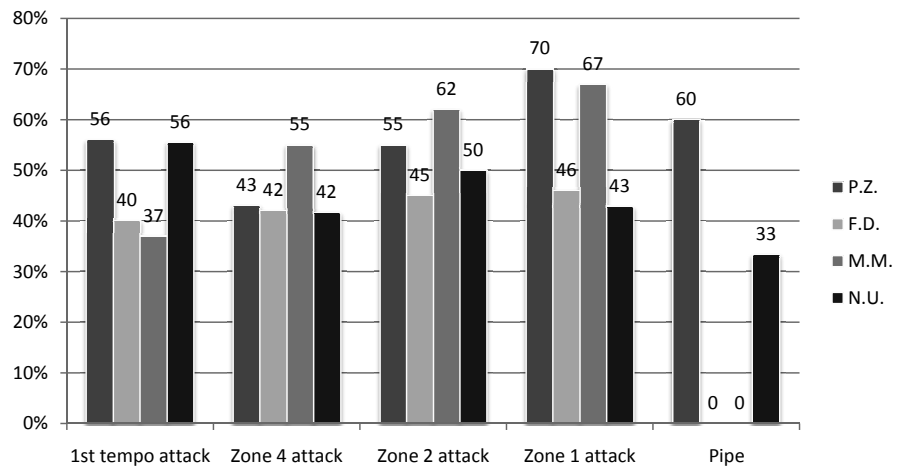

Figure 11. Cooperation reliability in particular combinations in attack (ARI) with setter in position 0 '

\section{Effectiveness of opponent block surprise depending on setter position}

The block surprise index (BSI) represents all types of cooperation where the opponent was confused, and their attempts to counteract were severely hindered. Surprising an opponent's block is a situation in which the opponent makes a single or double block inaccurately, that is with a large gap between players (the so-called "hole in the block") or in the wrong place. In positions 0 and 3, the highest opponent block surprise effectiveness was achieved by N.U.'s team, and it was $72 \%$ and $76 \%$, respectively. The block surprise effect achieved by P.Z.'s team had a BSI of $45 \%$, which was the highest value of this indicator of all teams after they played from the 0' position (see Fig. 12).

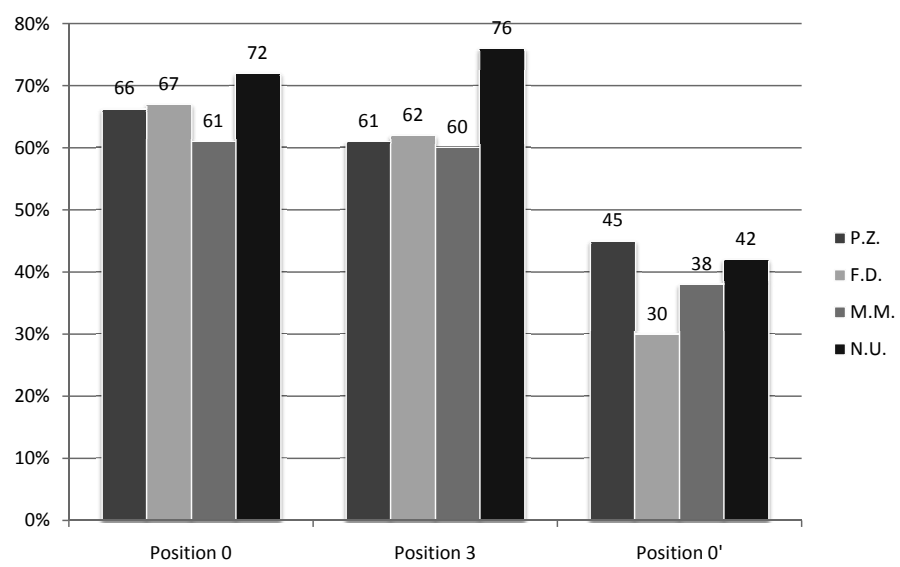

Figure 12. Opponent block surprise effectiveness (BSI) in particular positions

\section{Discussion}

The presented analysis of the research results was aimed at identifying mapping models which showed the effective cooperation of players in creating point situations, depending on the position of the setter on the court. A study of unique cases was applied in the work. Teams having the highest level of sport performance (the best teams of the top league in Poland) carry out unique activities during the game, and therefore the use of this method was justified in this case. The study examined four teams, each of which has a unique way of functioning in the game and a specific model of cooperation in the phase of creating point situations. A case study based on the technique of observation called "shadowing", where the observer describes 
events without interfering with them in a direct way, made it possible to create mapping models representing the teams' unique ways of cooperating. The detailed analysis of the research results aimed to induce reflection and indicate the direction of further research on this problem on larger and more diverse research groups (taking into account performance level and gender).

Expanding on the research undertaken by Mazur and Superlak [13], we have presented models that mapped the cooperation of four different teams in creating point situations. The results indicated that the teams differed from each other in the choice of the ways of interacting in the attack depending on the position of the setter. Differences were also noted in the level of the efficiency of these types of cooperation as well as in the effectiveness of surprising the opponent's block by the attacking teams. Three positions on the court $(0,0$ ', and 3$)$ were chosen for the analysis of the results; these were the positions where the most actions were taken by the setters, which confirmed the findings of Mazur and Superlak's analysis [13]. In each of the positions, the teams differed in the choice of ways to cooperate in creating point situations. The greatest similarity among the models, including the modes of cooperation of the researched teams, except for one case (the team of player M.M.), was noticed after playing from position 0 . Nevertheless, when we analysed the reliability of various ways of interacting in the attack, the values of the ARI were varied. The analysis of the cooperation of the players in the attack after playing the ball from the 0 ' and 3 positions confirmed that each team had its own unique way of creating point situations in the attack. Obviously, there were some similarities in the choice of some of the combinations, but it was evident that each team cooperated in a specific way, at the same time achieving different effectiveness (noticeable in the values of the ARI).

The ARI values were strongly related to the surprise effect on the opponent's block (BSI). Surprising the block makes it possible to achieve high attack reliability. The effectiveness of surprising the opponent's block differed in the teams examined. The highest values of the BSI were achieved by the teams in positions in which the setters were near the net (positions 0 and 3). Significantly lower values were obtained with the setter in position 0', that is at least $1.5 \mathrm{~m}$ away from the net. This is due to the fact that teams then create more combinations with the use of "wing players", and the tempo of this kind of cooperation is also slightly lower. In an analysis of the cooperation model in creating point situations, the block surprise index provides very important information, because it allows for a more accurate analysis of the efficiency of this cooperation, as well as the understanding of the choice of the types of combinations by the setters in creating point situations.

In the contemporary literature, there are few scientific papers that focus on the analysis of the process of player cooperation in a team game. We have undertaken an original attempt to investigate some of the issues related to creating point situations in elite volleyball. The research results presented also include the assessment of the effectiveness of the players in the attack taking into account the position of the setter on the court. Many authors have dealt with the effectiveness of the actions of individual players performing various functions in the game [i.a., 4, $5,6,19]$. Others have examined the impact of individual actions on wins or losses in the match $[3,20]$. The research that is the most similar to the one presented in this article is the analysis of the effectiveness of the attack with respect of the presence of the setter in particular court zones [21, 22] and an attempt to determine the most effective play zone with relation to the type of service and its reception [23]. Another example is the paper by Papadimitriou et al. [24] concerning the impact of receiving a serve on the pace of play and the effectiveness of the attack. All these works actually refer to the effectiveness of setting the ball in the attack. However, none of these papers takes a holistic view of the process of cooperation between players in the attack or makes an attempt to present the team's activities in a holistic and comprehensive manner. The main purpose of this study was to show unique ways of cooperation practised by high-level teams. In the literature, there is still a lack of papers that would focus on the process of cooperation, present its value, and treat ways of cooperation as a whole, rather than focusing on the effectiveness of individual actions. Also, no study was found that would analyse the effectiveness of the players' cooperation in the attack with respect to the location of the ball after the serve and thus the position of the setter in such a detailed manner as was presented in this article (11 positions were considered). The majority of papers undertake to analyse the setting of the ball in the attack with respect to the original position of the player, according to the division into zones resulting from the rules of the game (6 areas of the court).

The analysis of the research results presented has led us to conclude that there are differences in the ways of creating point situations depending on the position of the setter. The identified models of the cooperation of the players in the attack differed from each other, and this serves as an incentive for undertaking further research on this problem. Analysing and attempting to identify models of a larger number of teams may make it possible to create an optimal model of cooperation in the attack depending on the position of the player acting as the setter.

\section{Conclusions}

The research results presented in this paper make it possible to conclude that teams that achieve high levels of effectiveness in volleyball have specific models of cooperation in creating point situations with respect to the position of the setter in the court, and these models are varied. Based on an analysis of the detailed results of the study, the following answers can be formulated with regard to the research questions:

1. Each team had a specific model of cooperation in creating point situations with respect to the position of the setter on the court. Depending on the position of the setter, the teams used various ways of cooperation in the attack. When the 0 position was used, the choices of the combination were most similar to each other. When the setter was in positions 0 ' and 3 , the variation between the teams was greater.

2. The teams differed in terms of the reliability of attack in the implementation of particular combinations when the position of the setter on the court was taken into account.

3. When implementing the specific ways of cooperation in the attack, the teams achieved different levels of effectiveness in surprising the opponent's block. The block surprise indices for setter positions 0 and 3 (that is under the net) are much higher compared to that of the 0 ' position. The team that was found to be the most effective in surprising the opponent's block in positions 0 and 3 was the team of N.U., and in position 0', this was the team of P.Z.

This study may enable a more precise formulation of the training tasks and determination of the goals of the training process in terms of the organisation of cooperation between players in creating point situations in the game. The problem undertaken in the study is new and may serve as an incentive for carrying out further research in this area. 


\section{Literature}

1. Panfil R. (2011). The effectiveness of cooperation in the team game (pragmatic study of unique cases). Antropomotoryka 21(55), 73-87.

2. Panfil R. (2012). Pragmatics of cooperation in team sports. Wrocław: WSZiC. [in Polish]

3. Silva M., Marcelino R., Lacerda D., Joao P.V. (2016). Match analysis in volleyball: A systematic review. Montenegrin Journal of Sport Science and Medicine 5(1), 35-46.

4. Costa G., Ceccato J.S., de Britto Evangelista B.F., Freire A.B., Silva de Oliveira A., Milistetd M. et al. (2016). Tactic determinants of game practiced by middle attacker in men's volleyball. Brazilian Journal of Kinanthropometry and Human Performance 18(3), 371-379.

5. Mesquita I., César B. (2007). Characterisation of the opposite player's attack from the opposition block characteristics. An applied study in the Athens Olympic games in female volleyball teams. International Journal of Performance Analysis in Sport 7(2), 13-27.

6. Marcelino R., Mesquita I., César B., Afonso J. (2008). Attack-tempo and attack-type as predictors of attack point made by opposite players in volleyball. World Congress of Performance Analysis of Sport VIII, 3-6 September.

7. Afonso J., Mesquita I., Marcelinho R., Silva J.A. (2010). Analysis of the setter's tactical action in high-performance women's volleyball. Kinesiology 42, 82-89.

8. Pszczołowski T. (1978). A small encyclopedia of praxeology and organizational theory. Wrocław: Ossolineum. [in Polish]

9. Panfil R., Paluszek K. (2005). Efficiency models of futsal players' activities. In S. Żak, M. Spieszny, T. Klocek (eds), Team games in physical education and sport (pp. 262-270). Kraków: AWF Kraków. [in Polish]

10. Becella Ł. (2005). An efficiency model of creating and using the situation to score at the European Football Championship 2004. In S. Żak, M. Spieszny, T. Klocek (eds), Team games in physical education and sport (pp. 204-211). Kraków: AWF Kraków. [in Polish]

11. Nowak M. (2014). Positioning skills in the game of tennis. A pragmatic study of rare cases. Rozprawy Naukowe AWF Wroctaw 44, 85-92. [in Polish]

12. Nowak M., Panfil R. (2012). Scoring abilities in the game of tennis - A pragmatic study of unique cases. Human Movement 13(4), 313-322.
13. Mazur L., Superlak E. (2015). Organization and efficiency of cooperation abilities during attack phase depending on setter position on the court in a volleyball game. Rozprawy $\mathrm{Na}$ ukowe AWF Wrocław 51, 118-126. [in Polish]

14. Panfil R., Superlak E. (2011). Strategies for using interaction skills in creating point situations (a pragmatic study of a volleyball game). Antropomotoryka 21(53), 110-119.

15. Panfil R., Superlak E. (2012). The relationships between the effectiveness of team play and the sporting level of a team. Human Movement 13(2), 152-160.

16. Panfil R. (2008). Effective coaching of task teams based on the example of sports teams. Wrocław: University School of Physical Education in Wrocław. [in Polish]

17. Superlak E. (2005). Setter - situational action analysis. Biuletyn szkoleniowy PZPS 1, 4-8. [in Polish]

18. Superlak E., Wojtyczka M. (2011). Evaluation of players' cooperation abilities in the attack in the Polish men's national volleyball team. Rozprawy Naukowe AWF Wroctaw 32, 35-36. [in Polish]

19. Rentero L., Joao P.V., Moreno M.P. (2015). Analysis of the influence of the libero in different phases of game in volleyball. Revista Internacional de Medicina y Ciencias de la Actividad Fisica y del Deporte 15(60), 739-756.

20. Hayrinen M., Hoivala T., Blomqvist M. (2004). Differences between winning and losing teams in men's European toplevel volleyball. Conference: Performance Analysis of Sport VI, Belfast.

21. Palao J.M., Santos J.A., Ureña A. (2005). Effect of setter's position on the spike in volleyball. Journal of Human Movement Studies 48(1), 25-40.

22. Silva M., Lacerda D., Joao P.V. (2013). Match analysis of discrimination skills according to the setter attack zone position in high level volleyball. International Journal of Performance Analysis in Sport 13, 452-460.

23. Afonso J., Esteves F., Araújo R., Thomas L., Mesquita I. (2012). Tactical determinants of setting zone in elite men's volleyball. Journal of Sports Science and Medicine 11, 64-70.

24. Papadimitriou K., Pashali E., Sermaki I., Mellas S., Papas M. (2004). The effect of the opponents' serve on the offensive actions of Greek setters in volleyball game. International Journal of Performance Analysis in Sport 4(1), 23-33.

Submitted: October 30, 2017

Accepted: March 7, 2018 